\title{
Aplicação do modelo de crenças em saúde na adesão do trabalhador hipertenso ao tratamento
}

| ${ }^{1}$ Ana Karine de Figueiredo Moreira,

${ }^{2}$ Zélia Maria de Sousa Araújo Santos, ${ }^{3}$ Joselany Afio Caetano|

Resumo: Estudo descritivo e qualitativo que objetivou analisar as mudanças comportamentais em trabalhadores hipertensos na adesão ao tratamento, após aplicação de uma tecnologia em saúde embasada no Modelo de Crença em Saúde. O cenário da pesquisa foi uma instituição filantrópica e, após a proposta de educação em saúde, os participantes foram entrevistados. Selecionamos as seguintes categorias temáticas: percepção da severidade da HAS, percepção dos benefícios da adesão, percepção dos custos da mudança, identificação das mudanças visando à adesão e motivação para o estabelecimento de metas para a mudança. Os dados alcançados reforçam a educação em saúde do trabalhador hipertenso como estratégia de mudança de hábitos e valores pela aquisição de novos conhecimentos e adoção de atitudes favoráveis à saúde, através de uma educação crítica e transformadora, em que o sujeito assume participação ativa no processo de aprendizagem.

> Palavras-chave: hipertensão arterial; saúde ocupacional; adesão ao tratamento.
1 Fisioterapeuta. Mestrado em Saúde Coletiva, Universidade de Fortaleza (UNIFOR).

Endereço eletrônico:

anakmoreira@hotmail.com

2 Enfermeira. Graduação em Enfermagem e Mestrado em Saúde Coletiva, UNIFOR. Endereço eletrônico: zeliasantos@unifor.br

${ }^{3}$ Enfermeira. Graduação em Enfermagem e mestrado em Enfermagem, Universidade Federal do Ceará (UFC). Endereço eletrônico: joselany@ufc.br 


\section{Introdução}

A hipertensão arterial sistêmica (HAS) é uma doença de alta prevalência em adultos, com severas repercussões sobre o sistema cardiovascular. Nos Estados Unidos, estudos estabelecem sua prevalência em $25 \%$ em pessoas acima de 18 anos. No Brasil observa-se uma prevalência que oscila entre $22 \%$ a $44 \%$, utilizando-se o critério atual para o diagnóstico da HAS, que é pressão arterial (PA) sistólica acima de $135 \mathrm{mmHg}$ e/ou PA diastólica maior de $85 \mathrm{mmHg}$. Dessa forma, no mínimo, 20 milhões de adultos são hipertensos no Brasil (PINHEIRO; COUTO; SILVA, 2003).

Para o ano de 2000, a estimativa era de 18 milhōes de hipertensos no Brasil, $50 \%$ deles desconhecedores da sua situação; 5 milhões (27,7\% do total) eram hipertensos sem tratamento; 2 milhões $(11,1 \%)$ tinham HAS secundária e tratavam-se incorretamente e outros 2 milhões tratavam-se corretamente (LESSA, 2006). No ano de 2005, 8.976 pessoas morreram de doenças cardiocirculatórias no Ceará. Destas, 865 (9,6\%) vieram a óbito por HAS, e outras $866(9,6 \%)$ por doenças diretamente relacionadas à HAS. Ressalte-se que, além da mortalidade supracitada, outros 7.604 óbitos se deram por doenças provavelmente associadas à HAS (CEARÁ, 2005).

Uma das dificuldades encontradas no atendimento às pessoas hipertensas é a falta de adesão ao tratamento, pois estudos demonstram que cerca de 20 a $50 \%$ dos pacientes com HAS descontinuam a medicação anti-hipertensiva durante o primeiro ano de uso, e um número substancial daqueles que permanecem em uso da medicação o fazem de modo inadequado (ANDRADE et al., 2002). Outro estudo constatou que $50 \%$ dos hipertensos conhecidos não fazem nenhum tratamento e, dentre aqueles que o fazem, poucos têm a pressão arterial (PA) controlada. Entre 30 e $50 \%$ dos hipertensos interrompem o tratamento no primeiro ano e 75\%, depois de cinco anos (PERES; MAGNA; VIANA, 2003).

Aderir ou cumprir adequadamente o tratamento é muito mais do que apenas utilizar o medicamento prescrito. Implica seguir as demais condutas terapêuticas indicadas - uso de gordura vegetal e de adoçantes dietéticos e adequado de sal, abstenção do álcool e do tabaco, peso controlado, prática regular de exercício físico, ingesta adequada de café (até $100 \mathrm{ml} / \mathrm{dia}$ ), preferência por vegetais e por carnes brancas e gerenciamento do estresse. Então é importante que os hipertensos estejam sensibilizados para aderir ao tratamento, já que vários fatores têm sido 
associados com a adesão ao tratamento, entre eles os psicossociais, relacionados com a pessoa, seu perfil socioeconômico, sua escolaridade e suas crenças. As crenças e percepçōes parecem influenciar diretamente no comportamento e nas atitudes dos seres humanos.

A morbi-mortalidade tendencial da população trabalhadora aponta para uma prevalência cada vez mais frequente de agravos cardiovasculares, e dentre eles a HAS é a mais frequente. Então, considerando essa realidade e o problema da HAS para a saúde pública, questionamos: qual é o conhecimento do trabalhador hipertenso sobre a HAS e o tratamento? Será que ele adere ao tratamento da HAS? Se não adere, que percepção ele tem sobre o custo e benefícios de uma mudança comportamental necessária ao controle da HAS? Será que haverá mudanças comportamentais em relação à adesão, com a aplicação de uma tecnologia em saúde (TS) embasada no Modelo de Crença em Saúde (MCS)?

Refletindo sobre essas questôes, optamos por este estudo, ${ }^{1}$ com o objetivo de analisar as mudanças comportamentais em trabalhadores hipertensos na adesão ao tratamento, após aplicação de uma TS embasada no MCS.

O MCS foi publicado, em 1966, por Rosenstock, que buscava explicar o comportamento humano no processo saúde, partindo do pressuposto de que para o indivíduo emitir comportamentos preventivos em relação a uma dada doença, necessita acreditar que ele é pessoalmente suscetível àquela doença e que sua ocorrência deverá ter, pelo menos, moderada seriedade em algum componente de sua vida. E que para realizar açôes preventivas ou modificar comportamentos, o indivíduo necessita acreditar nos benefícios de tais mudanças, ou seja, que elas são capazes de reduzir sua suscetibilidade àquela doença ou reduzir sua seriedade. Segundo esse modelo, há barreiras psicológicas importantes, capazes de impedir que o indivíduo tome ações relacionadas à prevenção de doenças (ROSENTOCK, 1990).

Basicamente, o Modelo de Crenças em Saúde lida com quatro variáveis: suscetibilidade, seriedade, benefícios e barreiras percebidas, apesar de haver outras variáveis que podem afetar as percepções individuais, influenciando indiretamente a ação final. Buscamos o MCS como referencial teórico-metodológico, por considerarmos de grande relevância para explicar a adoção de comportamentos que possam auxiliar na prevenção e controle das doenças, e também predizer a aceitação de recomendações sobre cuidados com a saúde. 


\section{Trajetória metodológica}

Trata-se de uma pesquisa participante, desenvolvida em hospital público em Fortaleza-CE, atendendo exclusivamente a clientela do Sistema Único de Saúde (SUS) e que conta com 253 leitos distribuídos nas clínicas médica, cirúrgica, pediátrica, UTI adulto, UTI neonatal e UTI pediátrica. Desenvolve, ainda, assistência ambulatorial e domiciliar, como também programas especiais e personalizados, com equipes multiprofissionais para usuários portadores de enfermidades crônicas (pé diabético e AVC).

Para a realização do estudo, primeiramente identificamos 40 trabalhadores hipertensos através do cadastro no SESMT. A seguir iniciamos o processo de recrutamento dos sujeitos através de convite para participar de uma reunião, em que informamos o objetivo da pesquisa e a forma de sua participação, ocasião em que tivemos 20 trabalhadores hipertensos interessados em participar do estudo.

Antes de iniciar a coleta de dados, foi informada a aprovação da pesquisa pelo Comitê de Ética da Universidade de Fortaleza, sob o no. 107/2007, e foram solicitadas a leitura e a assinatura do Termo de Consentimento Livre e Esclarecido, sendo também seguidas as demais recomendações da Resolução no196/96, que normatiza a pesquisa envolvendo seres humanos (BRASIL, 1996). Somente após o cumprimento das formalidades ético-legais, iniciaram-se as oficinas nas quais, através de técnicas de dinâmica de grupo, foram abordados assuntos sobre a HAS, seus riscos, prevenção e adesão ao tratamento.

Foi um total de oito encontros e, ao final, os participantes foram entrevistados com ajuda de instrumento construído para esse fim, tendo como base o Modelo de Crenças em Saúde, contendo dados de identificação e as seguintes questões norteadoras: a) Percepção da severidade da HAS (o que você aprendeu sobre HAS? Quais os riscos que a HAS oferece a você??); b) Percep̧ção dos beneficios (quais os benefícios em controlar a HAS? A adesão ao tratamento pode beneficiar você? Como?); c) Percepção dos custos da mudança (quais as suas dificuldades - pessoais, familiares, relação, profissional / cliente, acessibilidade - para mudar de atitude e aderir ao tratamento?), d) Tomada de decisão / plano de ação (sua participação nos encontros contribuiu para a sua adesão ao tratamento? Você tomou algumas decisões após nossos encontros? Você se motivou o suficiente para agir / mudar de comportamento? Na prática, quais estratégias e planos de metas você criou para melhorar sua saúde?). 
As entrevistas foram gravadas conforme o consentimento dos participantes e tiveram a duração média de 60 minutos. Utilizamos o diário de campo para o registro de informaçôes necessárias ao processo de análise e inferência. Os dados foram organizados a partir do método da Análise de Conteúdo (BARDIN, 1995). Os conteúdos foram selecionados, codificados e inseridos em categorias, e a análise foi respaldada no Modelo de Crenças em Saúde e fundamentada na literatura sobre HAS. Os sujeitos foram codificados de E1 a E20.

\section{Análise e discussão dos resultados}

Dentre os 20 trabalhadores hipertensos que participaram das oficinas, seis (30\%) eram do sexo masculino e $14(70 \%)$ do feminino. Dos sujeitos, 15 encontravam-se casados, 15 eram de cor parda, quatro brancos e um negro. Dos participantes, 16 eram naturais de Fortaleza-CE e os demais de outros municípios do interior do estado, sendo que 18 residiam na capital cearense e dois em município da área metropolitana.

Em relação à profissão, das 14 mulheres, quatro eram auxiliares de enfermagem e quatro enfermeiras $(28,5 \%)$, três auxiliares de laboratório $(21,4 \%)$, duas auxiliares de farmácia e uma ouvidora $(7,1 \%)$. Entre os homens, encontramos dois auxiliares de enfermagem (33,3\%), um auxiliar de farmácia (16,6\%), um auxiliar de almoxarifado (16,6\%), um auxiliar de limpeza $(16,6 \%)$ e um auxiliar de laboratório (16,6\%).

Cinco mulheres afirmaram que eram hipertensas há quatro anos, mas somente há dois anos se submeteram ao tratamento; quatro descobriram esse agravo há três anos, mas iniciaram o controle há um ano; e as demais tinham acima de dez anos de HAS e quatro anos de acompanhamento. Quanto aos homens, a descoberta da HAS se deu em menos de quatro anos e quatro deles não aderiram às condutas terapêuticas de controle. Doze mulheres tinham sobrepeso, e o estresse por sobrecarga de trabalho foi relatado por treze delas. Nos homens, o sobrepeso estava presente em quatro e o estresse em cinco deles.

Entre os participantes, notamos uma maior resistência dos homens em aceitar a HAS, com nítida percepção de sentimentos de invalidez e impotência relacionados à doença crônica, refletindo na baixa adesão ao tratamento proposto. Dentre os seis participantes, cinco não seguiam as orientações, justificando-as pela ausência de manifestações clínicas e pela falta de tempo livre. Dentre as 
mulheres, dez se queixaram de dificuldades em mudar os hábitos alimentares; doze indicaram a falta de tempo e a sobrecarga de trabalho.

A partir da transcrição das entrevistas e após a leitura exaustiva das falas, apareceram conteúdos recorrentes e em alguns momentos até contraditórios, que foram inseridos nas dimensões do referencial teórico, e as categorias que emanaram da fala das entrevistadas: descrição do saber sobre a hipertensão e controle, percepção da severidade da HAS, percepção dos benefícios da adesão, percepção dos custos da mudança, identificação das mudanças com vista à adesão e motivação para o estabelecimento de metas para a mudança.

\section{Descrição do saber e do controle da HAS}

Esta categoria apresenta o conhecimento prévio dos sujeitos sobre os fatores de risco da HAS e as condutas de prevenção (uso adequado de sal, de gordura vegetal e de adoçantes dietéticos, abstenção do álcool e do tabaco, peso controlado, prática regular de exercício físico, ingesta adequada de café, preferência por vegetais e por carnes brancas, e gerenciamento do estresse).

Entre os sujeitos, apenas um reconheceu a história familiar, dentre os demais fatores de risco constitucionais, como fator predisponente para HAS. Já entre os fatores de risco ambientais - coadjuvantes e promotores da HAS - o consumo excessivo de sal foi citado por 18 participantes; a ingesta excessiva de café por dois; o consumo de álcool e o tabagismo por nove, o não-gerenciamento do estresse por dez e o sedentarismo por 13. Apenas um participante citou a raça como contribuinte para a elevação dos níveis pressóricos.

$\mathrm{O}$ consumo de alimentos não-saudável se devia à falta de opções destes nos locais de trabalho, onde frequentemente faziam suas refeições, por permanecerem a maior parte do seu tempo. Quatro afirmaram ausência de dificuldades na adesão, contudo, restringiam a adesão ao uso sistemático do esquema medicamentoso prescrito: “[...] eu sigo à risca o tratamento, pois sempre ando com o remédio dentro da bolsa [...] tomo direitinho e não saio sem ele"(E1).

Reis, Figueiredo Neto e Silva (2006) realizaram estudo sobre adesão ao tratamento farmacológico anti-hipertensivo em São Luís (MA), usando como medida o somatório do número de comprimidos consumidos nos cinco dias anteriores à entrevista, e classificaram o aderente o usuário cujo percentual de consumo totalizou $80 \%$ ou mais do que fora prescrito, encontrando taxa de adesão 
de $67,3 \%$. As razões de interrupção do tratamento foram: falta de medicamento na rede pública (46\%); esquecimento (30\%); dificuldade de cumprir horários (10,7\%); efeitos colaterais ( $9 \%)$; e o medo da dependência (3\%). No presente estudo, a frequência de adesão foi de $75 \%$, número diferente da realidade de outros trabalhos desenvolvidos. Isto se deve principalmente à forma como a adesão foi medida, ou seja, pelo relatório do próprio paciente, o que tende a superestimar o número de comprimidos tomados (OIGMAN, 2006).

De acordo com Podell, citado por Peres, Magna e Viana (2003), apenas um terço dos pacientes sempre tomava a medicação conforme foi prescrito; outro terço, às vezes; e um terço, raramente ou nunca. Tais dados podem ser atribuídos ao cansaço do paciente em viver na condição de "doente", situação que o uso da medicação de algum modo salienta. Ou seja, tomar o remédio o faz lembrar de sua condição crônica de saúde, podendo gerar ansiedade, medo e tristeza, levando-o a evitar esta situação.

Entre os 16 trabalhadores que referiram dificuldades na adesão ao tratamento, estas estavam relacionadas à sobrecarga de trabalho, que gerava cansaço físico e mental em 15 deles, desmotivando-os à prática de exercício físico. A sobrecarga de trabalho se devia à duplicidade de carga horária para suprir carências de recursos humanos em detrimentos de licença, férias e demissões, e/ou compromissos trabalhistas com mais de duas instituiçôes. Indubitavelmente, as mulheres trabalhadoras enfrentavam diariamente uma sobrecarga de trabalho secundária às múltiplas jornadas, constituídas por dois ou mais subempregos indispensáveis à manutenção de si, e frequentemente da família; tarefas domésticas e educação dos filhos. São fatos que podem dificultar as atividades de autocuidado indispensáveis à promoção de sua saúde, e em particular a adesão às condutas terapêuticas da HAS. Outras causas também citadas como barreiras à adesão: três queixaramse do difícil acesso às consultas médicas na rede pública; quatro suspendiam a medicação devido à ausência de manifestaçooes clínicas da HAS.

A recusa ao diagnóstico e ao seguimento às condutas terapêuticas de controle geralmente é atribuída à assintomatologia da HAS; para a maioria das pessoas, a presença e o desconforto destas as caracterizam como "doentes". Esse fato frequentemente é responsável pela divergência entre o tempo de diagnóstico e o tempo de início do tratamento, que foi observado nos sujeitos do estudo, em que 19 começaram o tratamento dois a quatro anos após saberem ser hipertensos. 
Cinco trabalhadores não aceitavam a HAS em detrimento da impossibilidade de cura, e ainda por depender do uso de medicações por tempo indeterminado.

[...] menina, eu tomei um susto quando tu disse que ela não tem cura, foi um choque mesmo, chega me senti mal, porque na mesma hora me vi como aquelas velhinhas entrevadas que vivem com uma caixinha cheia de remédio para tudo [...] e eu ainda me considero jovem [...] e se a danada não tem cura, a consequência é remédio para o resto da vida né $[\ldots]$ ninguém merece (E2).

Percebe-se que os participantes têm medo de algumas consequências da hipertensão, inclusive do tratamento prolongado, ter que tomar a medicação pelo resto da vida. Este aspecto pode favorecer parcialmente a adoção de comportamentos positivos em relação aos cuidados com a doença, pois existem outros fatores intervenientes na decisão de adotar um comportamento de saúde, sem contar a tendência em depositar o controle da pressão no médico e na medicação. Isto poderia ser explicado pela dificuldade que muitos pacientes relatam na prática clínica em mudar um hábito ou um estilo de vida. Principalmente, considerandose a existência de algumas prescrições de restrições altamente frustrantes, como os chamados prazeres da vida, tais como dietas alimentares, fumo e álcool.

Os homens afirmaram que não aderiam ao tratamento e resistiam ser portadores de HAS, porque esse agravo significava invalidez e impotência.

[...] olha eu não vou mentir não, eu só tomo o remédio quando me sinto mal, quando exagero no sal ou quando tenho uma raiva que a pressão sobe rapidinho [...] morro de medo do remédio me deixar mole, sem desejo, entende? Faço tudo para minha namorada não notar. Ela nem sabe que tenho pressão alta e guardo os comprimidos bem escondidos [...] porque esse negócio de tomar remédio é para velho, e eu ainda me sinto muito jovem (E3).

Esse fato repercutia negativamente na adesão ao tratamento, além da assintomatologia e do déficit de tempo. Culturalmente, os homens constituem o sexo forte, e os problemas de saúde somente afetariam sua fortaleza e masculinidade. A indisponibilidade de tempo para efetivação das condutas de controle do agravo perpassa a inadequação do estilo de vida à HAS e o tratamento, possivelmente decorrente da ausência de conscientização sobre o risco de complicações agudas e crônicas; repercute substancialmente na qualidade de vida e nos custos sociais com o absenteísmo ao trabalho, na licença para tratamento de saúde e na aposentadoria precoce por invalidez.

Uma pesquisa na Ilha de Mahé, República de Seychelles, com uma população adulta (504 homens e 563 mulheres, com idade entre 25 e 64 anos), para 
examinar seus comportamentos em relação à HAS, demonstrou que apesar de

as pessoas terem conhecimento sobre a doença, poucas mostram motivação real para mudar de hábitos. Como justificativa desse fato, estão a evolução silenciosa e a natureza crônica da hipertensão. A existência de modelos de estilo de vida feitos por atitudes, crenças, comportamentos e hábitos comuns a todos e condições sociais que tendem a se estabilizar através do tempo, o prazer individual por comportamentos prazerosos como a comida farta, salgada, o tabagismo e o sedentarismo são um poderoso impedimento para a adoção de comportamentos saudáveis como a atividade física regular, a redução da alimentação hiperssódica e hipercalórica, a moderação do consumo de álcool e a abstinência do fumo (LIMA; BUCHER; LIMA, 2004).

\section{Percepção da suscetibilidade e severidade da HAS}

De acordo com o modelo MCS, a adoção de um comportamento preventivo depende: de o indivíduo se considerar suscetível a um problema de saúde, isto é, acreditar que esse problema pode afetá-lo particularmente (percepção de suscetibilidade); de o indivíduo associar o problema de saúde à gravidade de suas consequências, isto é, perceber que esse problema pode ter consequências sérias (percepção de severidade); e de o indivíduo acreditar que esse problema de saúde pode ser prevenido por uma ação (percepção de benefícios), apesar de essa ação envolver aspectos negativos, tais como impedimentos, obstáculos, desconforto, gastos financeiros, entre outros (percepção de barreiras). Isto significa que os benefícios da ação são avaliados em função das barreiras para realizá-la. Além disso, a presença de estímulos para ação é importante para desencadear as percepções de suscetibilidade e severidade e motivar o indivíduo a agir.

[...] quando eu descobri que tinha HAS, aqui mesmo no hospital, nesses exames de rotina daqui, me lembrei logo dos pacientes da UTI... hoje mesmo deu entrada um paciente bem jovem, com AVC, e ouvi a família dele afirmar que era teimoso, vivia com dor de cabeça, já tinha tido uns picos de pressão, mas nunca se cuidou... quando vejo esses casos penso que podia ser eu ali, qualquer uma de nós né...se não cuidar já viu né! (E4).

Para os sujeitos da pesquisa, ser portador de uma condição crônica e, portanto, incurável, traz a sensação de medo, preocupação e restrição, sobretudo pela convivência de perto com pessoas jovens internadas com acidente vascular cerebral (AVC), que é uma complicação frequente da HAS. A possibilidade de 
evoluírem com a mesma complicação os deixou temerosos e aparentemente mais cuidadosos com sua própria saúde. Esses relatos são contraditórios, ao se observar os comportamentos de risco presentes nesses trabalhadores hipertensos.

[...] saber que tenho HAS não é nada agradável, mas como tenho desde os vinte e três anos, porque minha família toda tem, aprendi a lidar com essas coisas, mas medo dela eu tenho, não nego não.. não dá nem para esquecer, porque aqui no trabalho os meus colegas têm HAS, as enfermarias e UTIs estão cheias também, e quando chego em casa é que é! Minha mãe teve um AVC e teve que fazer fisioterapia um tempão pra recuperar, foi uma luta e eu me preocupo né [...] deixo a minha bem mansinha para ela não subir [...] Deus me livre de ficar como a minha mãe (HBM, 38 anos).

[...] eu só me enxerguei gorda depois que tu fez aquelas medidas todas na gente (IMC e Relação cintura/quadril) e mostrou para o grupo as tabelas com os valores normais, aí foi que eu vi que eu estou é longe do ideal [...] mas agora entendi que não é por vaidade, preciso perder peso para ter saúde (IMS, 39 anos).

[...] como é que eu me sinto com HAS? É com um monte de restrição né, se eu não me cuidar da comida e do remédio, lá vem a mulher me policiando [...] e como eu não sigo direitinho tudo, fico levando carão [...] isso é que me dá medo, porque sou ameaçado pela pressão alta e pela minha baixinha! (a esposa) (CHN, 37anos).

É interessante destacar que a suscetibilidade à hipertensão arterial não tem sido investigada, mas pode ser importante ponto de partida para a abordagem do tema junto à população em geral. $\mathrm{O}$ grande número de pessoas hoje hipertensas e que não se acreditavam suscetíveis a desenvolver a doença deve constituir um indicativo importante para os serviços de saúde, pois revela que apesar dos esforços empreendidos até agora na divulgação da doença hipertensiva, eles têm sido insuficientes para sensibilizar a população em geral sobre os riscos da doença. Aliás, os dados de estudos revelam que essa sensibilização não está surtindo os efeitos esperados, nem mesmo junto à população que, por questões hereditárias, possui maior predisposição para o desenvolvimento da doença. Como citado anteriormente, em estudo desenvolvido com 50 pessoas, 37 (74\%) relataram a presença de fatores hereditários e, no entanto, apenas cinco delas acreditavam ser suscetíveis em decorrência desse tipo de fator (GÓES; MARCON, 2002).

Assim, a condição crônica de saúde pode levar a diversas perdas nos relacionamentos sociais, nas atividades de lazer e de prazer (beber, fumar e comer), perdas financeiras e na capacidade física (TRENTINI; SILVA; LEIMANN, 1990). Todas essas perdas podem levar ao desânimo, tristeza e depressão, sendo um agravante no momento de mudar um hábito ou um estilo de vida. 
Benefícios percebidos: referem-se à crença na efetividade da ação e na percepção de suas consequências positivas. A direção da ação é influenciada pelas crenças do indivíduo em relação à efetividade das alternativas conhecidas para reduzir a ameaça à qual se sente submetido. Uma alternativa vista como benéfica é a relacionada à redução da suscetibilidade ou seriedade de uma doença. Em muitos casos, as crenças são influenciadas por normas e pressões sociais, podendo ser conflitantes (ROSENSTOCK, 1974).

[...] ah, eu queria era seguir mesmo, eu queria saber qual é o segredo, se existe uma fórmula mágica de obediência, porque eu sei que eu sou meio descuidada, eu nem meço a minha pressão todo dia, só quando sinto que comi com sal e ela sobe logo [...] deve ser muito bom ter a pressão normal, acho que esse é o maior benefício [...] eu queria seguir tudo pra não ter que me encher de remédio, eu queria ficar zen. (MV, 51 anos).

Os 20 participantes perceberam mais claramente os benefícios da adesão após as oficinas, reconhecendo que a adoção de um estilo de vida saudável é de suma importância para se ter saúde. Citaram principalmente uma maior longevidade e bem-estar como benefícios, caso adotassem o tratamento anti-hipertensivo.

[...] é muito importante [...] seguir todos esses cuidados só quem ganha é a gente porque vive sem preocupação, sem medo do pior [...] vive melhor porque ninguém quer morrer cedo ou ficar com um lado do corpo parado [...] eu mesmo quero aproveitar muito minha casa, minha família e ver meus filhos crescendo e agora eu sei que esse futuro melhor depende muito mais de mim, de me cuidar em tudo. (FJBS, 30 anos).

[...] acho que é tanto benefício que eu vi nos nossos encontros, para tudo tem um resultado positivo [...] a caminhada melhora o humor, a forma do corpo, baixa a pressão, ajuda a perder peso, que também baixa a pressão, tomar o remédio todo dia evita ter AVC e outras coisas lá [...] estou tentando fazer dentro do possível, mas eu sei que é tudo de bom! Parei de reclamar e estou melhor comigo mesmo, estou tentando me ajudar [...] porque vivia com os nervos à flor da pele e só quem subia era minha pressão [...] não vale a pena. (AFS, 44 anos).

Acredita-se que a adesão ao tratamento está atrelada ao papel educacional do profissional junto ao cliente, e para isto é fundamental que o profissional esteja atento às informações e mudança de atitude do cliente frente a uma doença; do seu reconhecimento de causas e das consequências da hipertensão arterial e da existência de medo de incapacidade física resultante de seu descontrole, resultando assim, no interesse e busca para a realização das práticas de autocuidado.

Algumas atitudes desenvolvidas por pessoas hipertensas podem constituir fatores facilitadores no desenvolvimento do autocuidado, pois resultam em maior 
possibilidade de controle da hipertensão, como a realização de exercícios físicos e restriçóes alimentares, ainda adotadas de forma incipiente em decorrência da dificuldade que os mesmos possuem para modificar alguns hábitos que outrora geravam prazer, como comer alimentos gordurosos e bem temperados.

\section{Percepção dos custos da mudança}

A baixa adesão ao tratamento clínico é o principal fator responsável pelo baixo controle da maioria das doenças crônicas. Dentre as diversas variáveis relacionadas ao paciente que podem interferir no comportamento de adesão ao tratamento, destacam-se a credibilidade do diagnóstico, o conhecimento do doente em relação à sua enfermidade, seus mecanismos fisiopatológicos, seus fatores de risco e benefícios do tratamento (VIEIRA; FREITAS; TAVARES, 2006).

Rosenstock (1974) afirma que efeitos indesejáveis do medicamento, barreiras financeiras, falta de motivação do paciente em tratar uma doença assintomática, bem como o grau de motivação dispensada nas estratégias de intervenção multidisciplinar, constituem entraves importantes para a adesão.

[...] até que eu queria mudar, mas estou cercada de estresse, é no trabalho, é quando saio daqui e chego atrasada no outro hospital, e as colegas ficam soltando piadinha, todo dia é isso, não tem como eu não me estressar, mas não demonstro que estou com raiva, porque eu preciso dos dois empregos, só um não dá pra manter minha casa [...] lá tudo sou eu. (MS, 38 anos).

Barreiras percebidas: as barreiras ou dificuldades são constituídas pelos aspectos negativos da ação em saúde, percebidas como impeditivas para a tomada de ação, sendo avaliadas em termos de custo, esforços dispensados, caráter invasivo a procedimentos diagnósticos e terapêuticos, a situaçôes que causam insatisfação, dor, aborrecimento; fatores que servem como barreiras para a ação e estimulam comportamentos conflitantes de enfrentamento e resistência (ROSENSTOCK, 1974).

Como a HAS é predominantemente assintomática, não há forte relação entre o sucesso terapêutico e o desaparecimento de eventuais sintomas. Ao contrário, muitas vezes o que ocorre é o aparecimento de sintomas com o uso de medicamentos, sendo essa mais uma barreira na adesão ao tratamento (COELHO; NOBRE, 2006).

Nove sujeitos, por sua vez, reconheceram que mesmo após as oficinas educativas, não conseguiram adotar um estilo saudável pela prática de 

tempo e influência do trabalho.

[...] eu até tinha vontade de fazer uma caminhada, entrar numa academia, todo dia eu me prometo começar, mas sempre tem alguma coisa pra atrapalhar, é meu pai que eu cuido, é o jantar, os filhos, o marido, aí acabo deixando pra amanhã os exercícios. (FARS, 37 anos).

[...] só pra conseguir uma consulta é uma novela, lá no hospital de Messejana consegui marcar mas só tem vaga pra depois de janeiro, e o médico que me atende lá é um grosso, da última vez ele me explicou umas coisas lá e eu perguntei de novo porque não tinha entendido direito, aí ele foi todo bruto, cheio de ironia dizendo que eu tinha entendido sim..não dá nem vontade de voltar lá. (IS, 38 anos).

[...] antes dos encontros eu tinha parado a medicação porque eu tava bem, eu estava tão bem que aí eu larguei, deixei de lado e pensava "pra que tomar remédio todo dia se eu não sinto nada, a pressão está normal?” Mas, depois eu vi que não posso fazer isso sozinha e marquei minha consulta com o cardiologista e estou aguardando pra ver o que ele diz, porque o que eu queria mesmo é não ter que tomar remédio direto... meu objetivo é só controlar, tirando o sal, fazendo as caminhadas. (I, 42 anos).

[...] mas ele não sabe que eu tomo remédio pra pressão, acho que eu tenho vergonha dele me ver como doente sabe, mas eu escondo o remedinho na minha bolsa e ele nem sabe. (I, 42 anos).

Eu tava tomando Captopril com Adalat e ela disse que por enquanto ela não ia pra eu não mudar, mas é muito ruim porque eu tenho que tomar dois comprimidos de manhã e dois a noite, eu queria mesmo era reduzir minha medicação para uma por dia, meu objetivo era reduzir essa dosagem da medicação, por isso eu quero fazer de verdade a caminhada para ver se eu consigo reduzir minha medicação. (H, 37 anos).

Quanto a esse aspecto, uma nova questão pode ser pensada: os trabalhadores hipertensos conseguiriam manter a PA controlada sem o uso da medicação apenas adotando as mudanças de estilo de vida sugeridas? O que seria mais fácil obter: uma transformação nos hábitos de vida, muitas vezes profundamente arraigados, ou o uso do medicamento, cuja utilização é relativamente simples? Estaria esse entrave ligado às condições do meio, que não facilitam mudanças permanentes no comportamento tornando, consequentemente, o uso exclusivo de medicamento a única opção concreta exequível?

\section{Motivação para o estabelecimento de metas de mudança}

Para Miller e Taylor (2003), tomar decisão em saúde é um processo no qual o indivíduo atravessa uma série de estágios em que as interações com pessoas ou eventos em cada uma dessas fases criam um ambiente motivacional favorável à tomada de decisão para sua saúde. 
O MCS considera a presença de estímulos à ação fator decisivo para despertar as percepções de suscetibilidade e severidade e motivar o indivíduo a agir. Nesse caso, os estímulos podem ser internos e externos; em nossa pesquisa, consideramos como estímulos externos as oficinas educativas direcionadas aos trabalhadores hipertensos e aplicadas no próprio ambiente de trabalho.

A necessidade de mudanças de hábitos ou estilo de vida é uma importante variável na determinação do comportamento do doente e, quanto maiores forem as alterações que ele necessitar fazer em seus hábitos e estilo de vida em função do tratamento (como, por exemplo, abstenção de fumo e bebidas alcoólicas, restrições dietéticas, inserção de exercícios físicos em sua rotina diária), menor será a possibilidade de adesão ao tratamento.

\section{Identificação das mudanças com vista à adesão}

Durante a aplicação da TS, observamos mudanças comportamentais nos sujeitos, principalmente em relação à aceitação da HAS, ao esquema medicamentoso, e à adoção de hábito alimentar saudável, havendo ainda resistência à adesão de exercícios físicos.

[...] para mim não tinha nada de ruim comer com sal. Agora diminui o sal da comida. Adorava o café lá do setor onde trabalho, mas passei a tomar menos depois que fiquei sabendo que ele aumenta a pressão. De comida gordurosa eu nunca gostei muito. Só falta começar a fazer exercício físico. (M.S., 38 anos).

[...] comecei a praticar exercício físico, coisa que nunca fiz. Estou fazendo natação duas vezes na semana. Só não faço mais vezes na semana por falta de tempo. Mudei também algumas coisas na minha alimentação e na da minha família. No refeitório eu passei a rejeitar aquela opção mais gordurosa. Minhas filhas e minha esposa também estão comendo com pouco sal principalmente depois que falei para elas sobre as doenças que uma alimentação inadequada pode causar. Nós também passamos a comer mais frutas e verduras na alimentação (L.R.A., 35 anos.

Os sujeitos apresentaram sugestōes para a adoção de um estilo de vida saudável, como a criação de um espaço pertencente ao hospital para a prática de exercícios físicos, com acompanhamento periódico do educador físico e elaboração de uma dieta específica para hipertensos, o que contribuiria para a manutenção do peso ideal e estratégias interpessoais de gerenciamento do estresse no trabalho.

[...] ia melhorar muito se tivesse uma academia ou sala de ginástica aqui no hospital, podia ser ao lado, nesse jardim enorme que tem ai e nem é usado [...] quando eu terminasse o trabalho ficava só mais uma horinha fazendo exercício lá , não ia ter descul- 
pa pra faltar né [...] perto de casa tem uma pracinha que muita gente faz caminhada,

mas não dá para mim [...] depois do plantão, para chegar em casa pego dois ônibus, ai eu já chego morto, sem coragem de nada (AMG., 48 anos).

A prática regular de exercícios físicos é recomendada e deve ser encorajada em todos os hipertensos, porque reduz a PA sistólica e diastólica em 6,9/4,9 mmHg, independentemente da redução de peso; havendo também redução do risco de doença arterial coronária, AVC e mortalidade geral. O Colégio Americano de Medicina do Esporte orienta a realização de atividade aeróbica de moderada intensidade, a partir de 30 minutos de duração, em no mínimo três dias na semana, mas de preferência que seja incorporada ao estilo de vida do hipertenso e realizada diariamente, para que sejam maximizados seus efeitos hipotensores. Ressalta, também, que o hipertenso só pode iniciar a prática de exercícios de forma supervisionada por programa de reabilitação cardiovascular e apresentando níveis tensionais pressóricos controlados (SOCIEDADE..., 2006; NÓBREGA; CASTRO, 2005; SOARES, 2005).

A educação em saúde, portanto, consolida-se como recurso oportuno e imprescindível à mudança de atitude, que vise não só ao controle da HAS, como também à busca do melhor nível de saúde e bem-estar. No entanto, deverá ser uma práxis em qualquer espaço institucional - escola, família e trabalho que torne a pessoa livre e consciente na hora da seleção das condutas para um estilo de vida saudável. Neste contexto, concordamos com Santos e Barroso (2003), ao afirmarem que a educação em saúde conduz a pessoa à mudança de comportamento, permitindo-lhe aumentar a habilidade de engajar-se no autocuidado, responsabilizando-se pela promoção de sua saúde e bem-estar, além de emponderada para o exercício da cidadania.

\section{Considerações finais}

O estudo possibilitou uma melhor compreensão dos portadores de HAS quanto à adesão ao tratamento, mediante a aplicação da TS embasada no MCS. A TS suscitou nos trabalhadores a ampliação de sua percepção sobre a vulnerabilidade e a gravidade da HAS, os benefícios da adesão ao tratamento, eliminar e/ou controlar as barreiras impeditivas de mudanças comportamentais, os estímulos para a ação e elaboração de estratégias para o controle da HAS, prevenindo as complicações, promovendo sua saúde e bem-estar, proporcionando-lhes qualidade de vida. 
Nesse contexto, a implementação da TS mediada pela educação em saúde, direcionada aos trabalhadores hipertensos, favoreceu a análise crítica e reflexiva sobre suas crenças, hábitos insalubres, atitudes inadequadas, sobretudo sua adesão às condutas terapêuticas de controle da HAS. Isso gradativamente gerou mudanças comportamentais significativas no estilo de vida, independentemente do ambiente social em que estejam, com a expectativa de aceitar a HAS e adaptar o estilo de vida às condutas terapêuticas de controle desse agravo.

Vale ressaltar que essas etapas de mudança comportamental foram identificadas ao longo da vivência da TS, com significativa relevância desse processo contínuo de educação em saúde, havendo necessidade urgente da consolidação dessas práticas transformadoras no ambiente de trabalho hospitalar, sensibilizando os sujeitos à participação no processo contínuo de adesão ao tratamento antihipertensivo e às medidas de promoção da saúde.

\section{Referências}

ANDRADE, J.P. et al. Aspectos epidemiológicos da aderência ao tratamento da hipertensão arterial sistêmica. Arq. Bras. Cardiol., v. 79, n. 4, p. 375-9, 2002.

BARDIN, L. Análise de conteúdo. Lisboa: Edições 70, 1995.

BRASIL. Ministério da Saúde. Conselho Nacional de Saúde. Comissão Nacional de Ética em Pesquisa. Resolução $n^{\circ}$ 196, de 10 de outubro de 1996. Pesquisa envolvendo seres humanos. Brasília, 1996.

CEARÁ. Secretaria de Saúde do Estado. Indicadores e dados básicos para a saúde no Ceará 2004. Fortaleza: SES-CE, 2005.

COELHO, E.B.; NOBRE, F. Recomendações práticas para se evitar o abandono do tratamento anti-hipertensivo. Rev. Bras. Hipertens., v. 13, n. 1, p. 51-4, 2006.

GÓES, E.L.A.; MARCON, S.S. A convivência com a hipertensão arterial. Acta Scientiarum, v. 24, n. 3, p. 819-29, 2002.

LESSA, I. Impacto social da não-adesão ao tratamento da hipertensão arterial. Rev. Bras. Hipertens., v. 13, n. 1, p. 39-46, 2006.

LIMA, M.T.; BUCHER, J.S.N.F.; LIMA, J.W. A Hipertensão arterial sob o olhar de uma população carente: estudo exploratório a partir dos conhecimentos, atitudes e práticas. Cad. Saúde Pública, v. 20, n. 4, p. 112-22, 2004.

MILLER, N.H.; TAYLOR, C.B. Modificação comportamental para redução dos fatores de risco cardiovasculares. In: POLLOCK, M.L.; SCHMIDT, D.H. (Org.). Doença cardiaca e reabilitação. Rio de Janeiro: Revinter, 2003. 
NÓBREGA, A.C.L.; CASTRO, R.R.T. Hipertensão arterial e exercício. In: FRANCIS-

CHETTI, E.A.; SANJULIANI, A.F. (Org.). Hipertensão arterial. São Paulo: BBS, 2005.

OIGMAN, W. Métodos de avaliação da adesão ao tratamento antihipertensivo. Rev. Bras. Hipertens., v. 13, n. 1, p. 30-4, 2006.

PERES, D.S; MAGNA, J.M; VIANA, L.A. Portador de hipertensão arterial: atitudes, crenças, percepções, pensamentos e práticas. Rev. Saúde Pública, v. 37, n. 5, p. 635-42, 2003.

PINHEIRO, L. A.; COUTO, A. A.; SILVA, E. N. Sobrevida e morbidade na hipertensão arterial tratada: um estudo crítico. Programa de Educação Continuada, v. 3, n. 1, p. 16-26, 2003.

REIS, L.J.B. Adesão ao tratamento farmacológico anti-hipertensivo. 2006. Dissertação (Mestrado) - Universidade Federal do Maranhão, São Luiz, 2006.

ROSENSTOCK, I.M. The health belief model: explaining health behavior through expectancies. In: GLANZ, K., LEWIS, F.M., RIMER, B.K. (Ed.). Health behavior and health education: theory, research and practice. San Francisco: Jossey-Bass, 1990. p. 39-62.

ROSENSTOCK, I.M. Historical origins of the health belief model. Health Educ. Monogr., v. 2, n. 4, p. 328-45, 1974.

SANTOS, Z.M.S.A; BARROSO, M.G.T. A interdisciplinaridade na fundamentação da promoção da saúde. In: BARROSO, M.G.T.; VIEIRA, N.F.C.; VARELA, Z.M.V. (Org.). Educação em saúde no contexto da promoção humana. Fortaleza: Demócrito Rocha, 2003. p. 55-9.

SOARES, L.C. Mudanças no estilo de vida e controle da pressão arterial. In: FRANCUSCHETTI, E.A.; SANJULIANI, A.F. (Org.). Tópicos especiais em hipertensão arterial. São Paulo: BBS, 2005.

SOCIEDADE BRASILEIRA DE CARDIOLOGIA; SOCIEDADE BRASILEIRA DE HIPERTENSÃO; SOCIEDADE BRASILEIRA DE NEFROLOGIA. V Diretrizes brasileiras de hipertensão arterial. São Paulo: SBC, 2006.

TRENTINI, M.; SILVA, D.G.V.S.; LEIMANN, A.H. Mudanças no estilo de vida enfrentadas por pacientes em condiçōes crônicas de saúde. Rev. Gaúcha Enferm, v. 3, n. 11, p. 18-28, 1990.

VIEIRA, V.; FREITAS, J.B.; TAVARES, A. Adesão ao tratamento clínico. Guia de qualidade de vida. São Paulo: Manole, 2006 (Série Guias de Medicina Ambulatorial e Hospitalar).

\section{Nota}

1 Este artigo é parte dos resultados da dissertação de mestrado de Ana Karine de Figueiredo Moreira, orientada por Zélia Maria de Sousa Araújo Santos e defendida no Mestrado em Saúde Coletiva da Universidade de Fortaleza-CE. Joselany Áfio Caetano colaborou na elaboração do projeto e revisão final do artigo. O trabalho foi aprovado pelo Comitê de Ética da Universidade de Fortaleza sob o no. $107 / 2007$. 


\section{Application of the model of health beliefs in the worker's compliance with hypertension treatment}

Qualitative and descriptive study aiming to examine the behavioral changes in hypertensive workers in the compliance with treatment after application of a health technology based on the Health Belief Model. The scenario of the research was a philanthropic institution, and after presenting health education issues, the participants were interviewed. Then we selected the following theme categories: perception of the severity of hypertension, awareness of the benefits of compliance, awareness of change costs, identification of the changes aiming the compliance and motivation for the establishment of objectives for the change. The data obtained reinforce the health education of hypertensive worker as a changing strategy of habits and values for the acquisition of new knowledge and adoption of positive attitudes towards health, through a critical and changing education, in which the subject actively participates in the learning process.

> Key words: Arterial hypertension; occupational health; compliance with treatment. 